\title{
Comportamiento Sísmico de los Edificios de Lorca
}

\author{
MARTHA LiLIANA CARREÑO TIBADUIZA ${ }^{1,2}$, NIEVES LANTADA ZARZOSA ${ }^{1}$, \\ JANIRA IRIZARRY ${ }^{3}$, JAIRO A. VALCARCEL ${ }^{1}$, ALEX H. BARBAT ${ }^{1,2} \&$ \\ XAVIER GOULA SURIÑACH ${ }^{3}$ \\ ${ }^{1}$ Universidad Politécnica de Cataluña \\ ${ }^{2}$ Centre Internacional de Mètodes Numèrics en Enginyeria (CIMNE) \\ ${ }^{3}$ Institut Geològic de Catalunya (IGC) \\ liliana@cimne.upc.edu
}

Recibido: $27 / 04 / 2012$

Aceptado: $18 / 10 / 2012$

\section{Resumen}

Después de ocurrido el terremoto de Lorca, el 11 de mayo de 2011, el Institut Geològic de Catalunya (IGC), la Universidad Politécnica de Cataluña (UPC) y la Asociación Española de Ingeniería Sísmica (AEIS) organizaron, junto con las asociaciones de ingeniería sísmica francesa (AFPS) y portuguesa (SPES), una visita técnica con el objeto de realizar observaciones que permitieran calibrar, verificar y validar los métodos utilizados en las evaluaciones de riesgo sísmico en zonas urbanas. Este artículo resume los aspectos más destacados en cuanto a la observación de la vulnerabilidad de edificios de vivienda, así como de edificios de especial importancia como son hospitales y escuelas.

Palabras clave: Lorca, daño observado, comportamiento sísmico, lecciones aprendidas.

\begin{abstract}
After the earthquake of Lorca, May 11, 2011, the Geological Institute of Catalonia (IGC), the Technical University of Catalonia (UPC) and the Spanish Association for Earthquake Engineering (AEIS) organized a technical visit in order to compile information that allow to calibrate, to verify and to validate the methods used in seismic risk assessments in urban areas. This article summarizes the highlights regarding the vulnerability of residential buildings and buildings of special importance such as hospitals and schools.
\end{abstract}

Seismic behavior of the buildings in Lorca

Keywords: Lorca, identified damage, seismic behavior, lessons learned.

\section{Referencia normalizada}

Carreño, M. L., Lantada N., Irizarry J., Valcarcel J. A., Barbat A. H. y Goula X. (2012). Comportamiento Sísmico de los Edificios de Lorca. Física de la Tierra, Vol.24, 289-314.

Sumario: Introducción. 1. Daños estructurales observados. 1.1. Hormigón armado. 1.1.1. Pilares Cortos. 1.1.2. Planta blanda. 1.1.3. Falta de confinamiento de los pilares. 1.1.4. Efecto del golpeteo. 1.2. Mampostería no reforzada. 1.3. Edificios de autoconstrucción. 2. Daños en elementos no estructurales. 3. Daños en el patrimonio cultural y religioso. 3.1. Iglesia de Santiago. 3.2. Iglesia del Carmen. 4. Daños en edificios de importancia especial. 4.1. Hospital Rafael Méndez. 5. Lecciones aprendidas. Agradecimientos. Referencias bibliográficas. 


\section{Introducción}

El día 11 de mayo de 2011 ocurrió en la región de Murcia, España, un terremoto con magnitud $\mathrm{Mw}=5.1$; su epicentro fue ubicado a tan sólo $2 \mathrm{~km}$ de profundidad y a unos pocos kilómetros de la ciudad de Lorca. A pesar del valor moderado de magnitud, la aceleración pico registrada en la ciudad de Lorca fue de $0,376 \mathrm{~g}$, valor que supera la aceleración básica de proyecto prevista para esta localidad en la Norma Sismorresistente Española NCSE-02, que es de 0,12 g.

En la Figura 1 puede verse el espectro correspondiente a la componente N-S del terremoto de Lorca (en azul) en comparación con los espectros sísmicos de diseño de la Norma Sismorresistente Española, NCSE-02, para diferentes tipos de suelo.

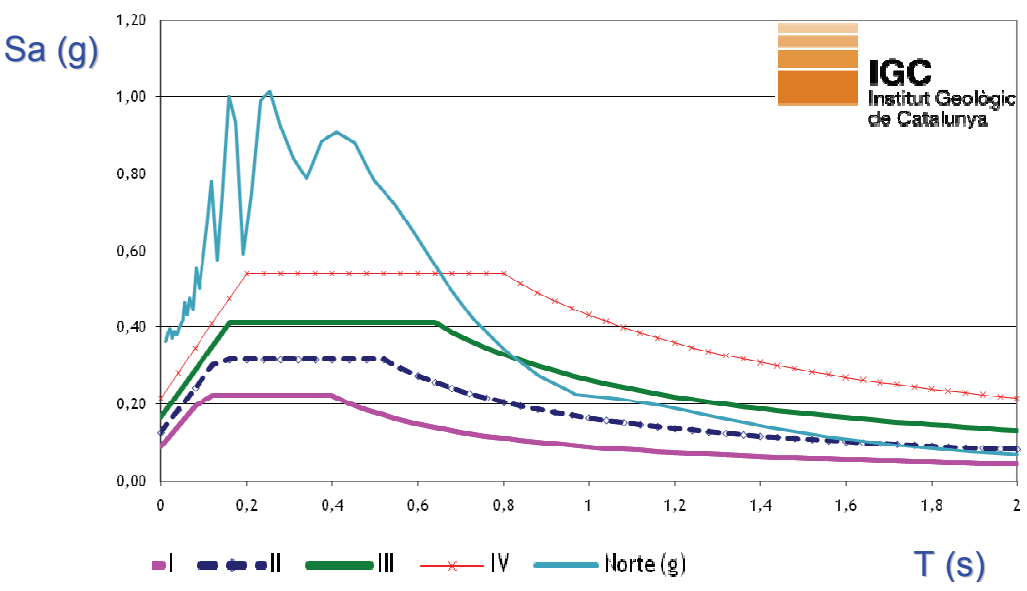

Fig. 1. Espectro de respuesta para la componente N-S del terremoto de Lorca y los espectros sísmicos de diseño de la norma NCSE-02 (Institut Geològic de Cataluña, IGC).

Debido a su ubicación, el municipio de Lorca, con 92.869 habitantes, de los cuales casi 60.000 se encuentran en su casco urbano (CREM 2012), se vio fuertemente afectado. Al sismo se le ha asignado una intensidad macrosísmica de VII grados en la escala EMS, a partir de los efectos que provocó. Como consecuencia del terremoto unas 300 personas resultaron heridas y 9 fallecieron, debido principalmente a la caída de cornisas y elementos no estructurales de edificios. Cerca de 10000 personas se vieron desplazadas de su hogar después del terremoto (4000 a un campamento habilitado por la Administración Local). Un número elevado de alumnos (del orden de 6600) se quedaron sin poder recibir clases, ya que muchas escuelas e institutos resultaron fuertemente dañados. También el hospital comarcal Rafael Méndez fue evacuado con urgencia.

A fecha de 21 de mayo de 2011, los arquitectos del Ayuntamiento de Lorca habían realizado al menos una visita de inspección a un total de 7.839 edificios, que representa un porcentaje muy elevado del total del núcleo urbano. Unos 300 edificios $(4 \%)$ se habían clasificado con daños estructurales graves y $465(6 \%)$ con 
daños estructurales moderados. En los dos casos se observaron daños no estructurales graves, que también podían poner en peligro la seguridad de las personas. Un número importante de edificios del patrimonio arquitectónico ha sido dañado en mayor o menor medida. La Figura 2 muestra la distribución de los daños de acuerdo con el visor de daños del Ayuntamiento de Lorca (26/04/2012). Según dicho visor, se han informatizado un total de 6419 inspecciones, los edificios han sido clasificados según los daños observados en 4 clases: negro (329), rojo (725), amarillo (1284) y verde (4044).

Los autores han estudiado distintos aspectos relacionados con la vulnerabilidad de edificios de vivienda, así como de los edificios de especial importancia como son hospitales y escuelas (AFPS 2011 y Barbat et al 2011).

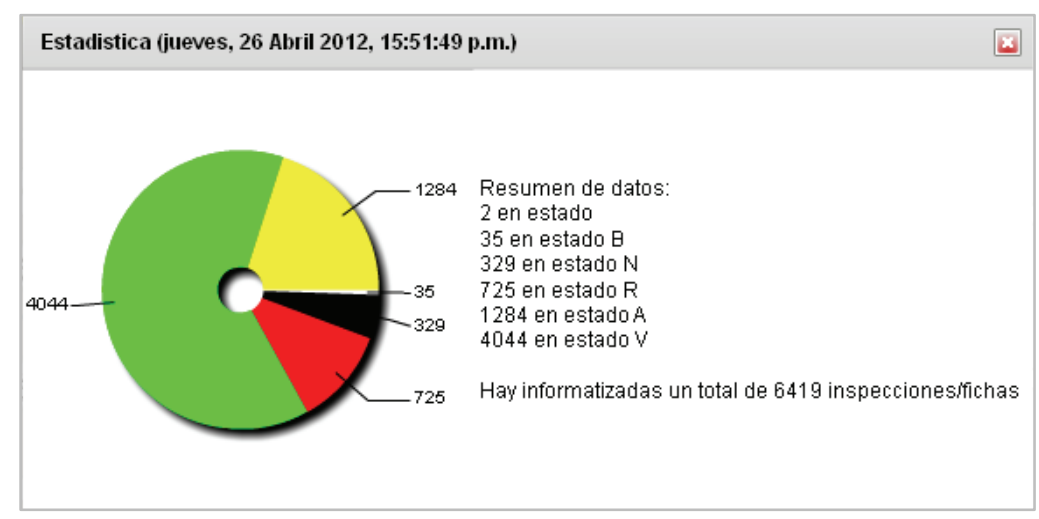

Fig. 2. Consulta de la distribución del daño para toda la ciudad (26/04/2012) según el visor de daños (Ayuntamiento de Lorca, 2012)

\section{Daños estructurales observados}

Los sistemas estructurales comúnmente más usados en la ciudad de Lorca, y en general en España, corresponden a edificios porticados de hormigón armado y edificios de mampostería no reforzada. Otro sistema estructural utilizado, aunque presente en menor medida, son los edificios con estructura metálica. También se encuentran edificios de autoconstrucción, en los cuales se pueden encontrar mezclados los sistemas estructurales antes mencionados. Esta sección resume los daños observados de acuerdo con el sistema estructural utilizado.

\subsection{Hormigón armado}

En general, en los edificios de hormigón armado se han observado daños estructurales de diferente severidad, que varían desde muy leves hasta colapso. Esto puede deberse al hecho de que, si bien la aceleración pico del terremoto a superado en tres veces la aceleración básica de proyecto, su duración ha sido muy corta. Por esto, el 
número de ciclos de vibración a los que han sido sometidos los edificios ha sido bajo, experimentando éstos pocas incursiones en el campo inelástico. Como consecuencia, los más dañados edificios han sido los más frágiles, de poca calidad sísmica, es decir, los de alta vulnerabilidad, que, por su naturaleza, han podido dañarse en pocos ciclos. Por ejemplo, los edificios de hormigón armado construidos en años anteriores a las normas, tal como son muchos de los del barrio de La Viña, han presentado un comportamiento inadecuado frente al terremoto y un gran número de ellos, debido al alto grado de daño estructural y no estructural sufrido, han recibido decretos de demolición.

Los edificios con forjados reticulares diseñados mediante la norma NCSE-02 tienen la ductilidad de proyecto limitada a 2 . De acuerdo con la relación entre el espectro de aceleraciones del terremoto de Lorca y las ordenadas del espectro de diseño (véase la Figura 1), en su zona de máxima respuesta, la demanda de ductilidad ha sido entre 3 y 5 , es decir, mayor que la de proyecto. Algunos de los edificios de hormigón armado cuyo período fundamental se encontraba en esta zona del espectro han sufrido daños mayores. Por otra parte, otros edificios, más flexibles, con un período fundamental mayor, se encontraban en una zona del espectro con una demanda de ductilidad menor y han sufrido daños más reducidos.

Otro factor que ha demostrado tener un impacto relevante sobre la variabilidad del grado de daño sufrido por diferentes edificios de la misma zona, es el del ángulo de incidencia de la onda sísmica sobre los edificios. Este es el caso, por ejemplo, del barrio de San Fernando, con edificios con la misma configuración estructural pero con diferente orientación, en donde se han registrado en los edificios niveles de daño muy diferentes.

La mayoría de los edificios de hormigón armado de Lorca y de otras zonas sísmicas de España corresponden a un sistema de pilares y forjados planos. El comportamiento sísmico de los edificios de hormigón armado depende, en gran medida, de las prácticas de diseño y construcción habituales en la zona. Generalmente, sin hacer referencia a zonas sísmicas concretas, pueden identificarse los siguientes errores típicos:

- pilares cortos

- pilares cautivos

- plantas bajas blandas

- falta de confinamiento de los pilares

- cerramientos no conectados a la estructura

- elementos no estructurales no anclados

- juntas sísmicas de dimensión insuficiente entre edificios.

Debe mencionarse el caso especial de los edificios con forjados reticulares, muy aceptados por sus ventajas tecnológicas y, especialmente, por sus ventajas arquitectónicas, al no atravesarse espacios con vigas de canto. Los forjados reticulares tienen nervios en dos direcciones ortogonales, están apoyados en pilares mediante secciones macizas denominadas ábacos y, en algunos casos, están reforzados mediante elementos metálicos denominados crucetas. En este caso, la falta de vigas y 
de nudos imposibilita realizar un diseño dúctil de la estructura por la ineficacia de confinar las secciones de los forjados, los cuales son elementos de menor canto. Por consiguiente, su diseño depende de su mayor rigidez y resistencia y de la posibilidad de transferir las tensiones tangenciales entre los pilares y el forjado. Esta es la razón por la cual se han observado en Lorca varios casos de estructuras con los pilares dañados en sus extremidades mientras que los forjados reticulares estaban intactos. Podríamos afirmar que nos encontramos frente a un caso de "pilar débil y forjado reticular fuerte" que, sin duda alguna, puede conducir a un colapso de tipo frágil del edificio.

Un aspecto que puede conducir a daños sísmicos es el dimensionamiento inadecuado de las juntas sísmicas que se dejan entre los edificios colindantes. Este hecho puede producir el fenómeno de golpeteo entre los edificios, que puede tener como consecuencia importantes daños e, incluso, el colapso de los mismos.

Los autores identificaron los tipos de daños más frecuentes en el parque de edificios de Lorca: pilares cortos, plantas blandas, algunas deficiencias en las armaduras de refuerzo y efecto de golpeteo. A continuación se describen estos tipos de daños.

\subsubsection{Pilares cortos}

La presencia de pilares cortos en los edificios puede ser la causa de grandes daños estructurales e, incluso, del colapso de las estructuras, debido al excesivo esfuerzo cortante al que están sometidos.

El efecto de pilar corto tiene su origen en su mayor rigidez en comparación con los pilares más largos que se encuentran al mismo nivel del edifico. Debido a dicha rigidez, los pilares cortos soportan una mayor carga sísmica, por lo que están sometidos a mayores esfuerzos, especialmente cortantes. Como consecuencia, sufrirán daños mayores que los pilares de mayor longitud. Diversas situaciones propician la existencia de pilares cortos: edificios que descansan sobre un terreno inclinado, entresuelos añadidos entre dos plantas regulares y pórticos con muros de relleno de altura parcial, entre otros.

Entre los edificios más dañados por el terremoto de Lorca, se pudieron observar numerosos casos del efecto de pilar corto. La Figura 3 y la Figura 4 muestran ejemplos de los daños en pilares cortos en un edificio de construcción reciente apoyado en múltiples pilares cortos. 

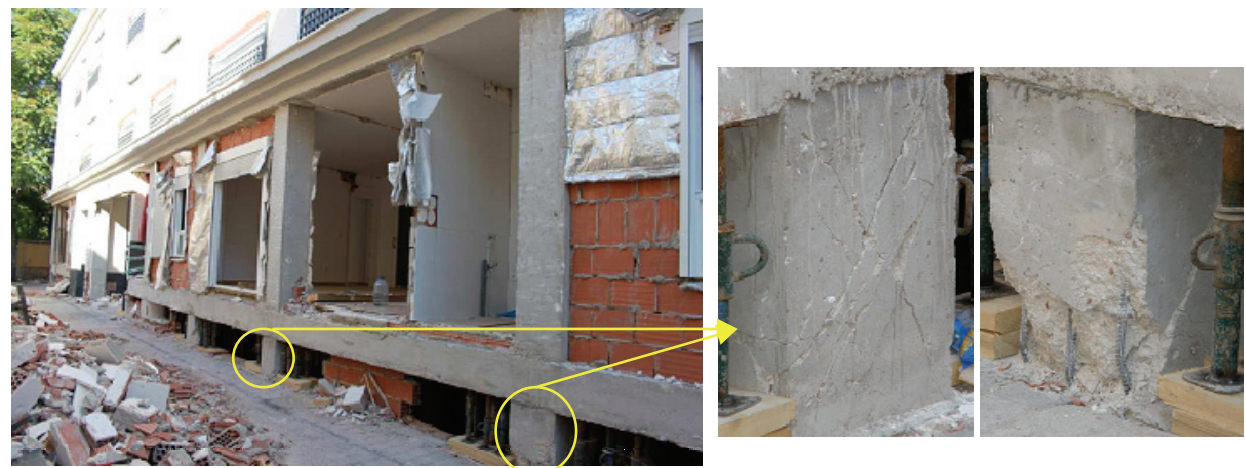

Fig. 3. Daños en un edificio con múltiples pilares cortos.

La Figura 5 muestra el único edificio que colapsó durante el terremoto, el cual corresponde a una estructura reciente de hormigón armado, localizado en el barrio La Viña, uno de los barrios más afectados de Lorca. Gracias al Google Street View podemos ver que antes del terremoto era un edificio en aparente buen estado (Figura 5a). Este edificio tenía una configuración similar a la del edificio de la Figura 4, apoyado en uno de sus lados sobre pilares cortos. Análisis preliminares (Murphy, 2011) indican que este edificio colapsó debido al fallo de estos pilares.
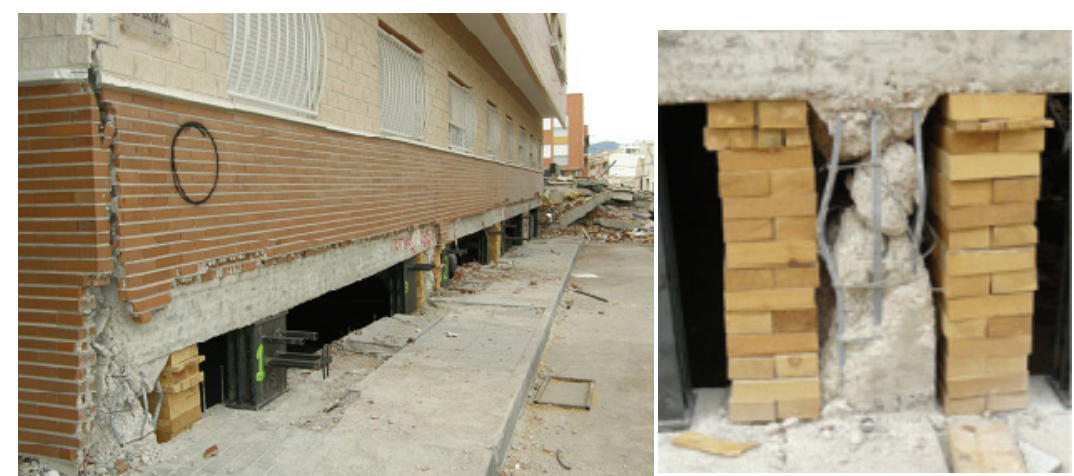

Fig. 4. Daños en otro edificio con múltiples pilares cortos. 


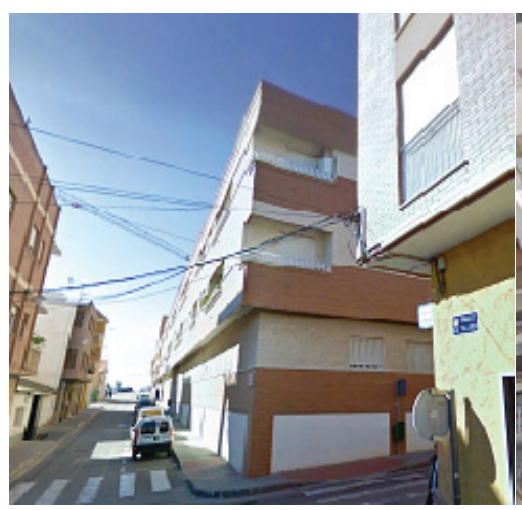

a)

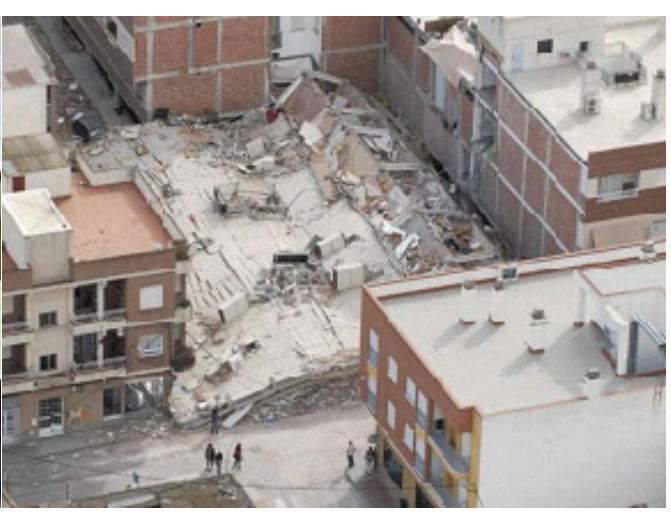

b)

Fig. 5. Único edificio de hormigón armado que colapsó durante el terremoto: (a) edificio antes del terremoto disponible en el Google Street View y (b) vista tras el terremoto de Lorca (La Verdad, 2011c)

Sin embargo, existe la posibilidad de reforzar los edificios existentes con pilares cortos para evitar daños durante futuros terremotos (Barbat et. al, 2011). Posibles medidas de refuerzo consisten en rigidizar los pilares cortos aumentando su sección transversal o, incluso, sustituir las líneas de pilares cortos perimetrales de los edificios, correspondientes a las plantas semisótanos, mediante pantallas a cortante.

\subsubsection{Planta baja blanda}

Una situación que añade dificultades al problema de los daños no estructurales es la de la planta baja débil, habitual en muchos de los edificios que se encuentran en zonas sísmicas. Este tipo de configuración estructural suele tener su origen en una mayor altura de la planta baja.

Debido a este efecto se concentran esfuerzos en una planta del edificio debido a que es más flexible que las demás. Generalmente el término se le aplica a los edificios con plantas bajas abiertas o menos rígidas que las plantas superiores, pero una planta blanda puede crear problemas en cualquier altura.

En la mayoría de los casos de terremotos moderados y leves, la presencia de dicha planta débil no conduce al colapso de la estructura sino a grandes desplazamientos horizontales seguidos de daños graves en los cerramientos y, en ocasiones, también en los elementos estructurales.

El efecto de planta blanda se observó en la mayoría de los edificios afectados por el terremoto de Lorca. La Figura 6 muestra los daños en un edificio que perdió los cerramientos de la planta baja debido a la mayor deformación de la misma por ser una planta blanda. La Figura 7 muestra otro edificio con daños concentrados en la planta blanda. Además de caer los cerramientos, se observaron daños en algunos pilares y algunos refuerzos longitudinales presentaban el efecto de pandeo. 


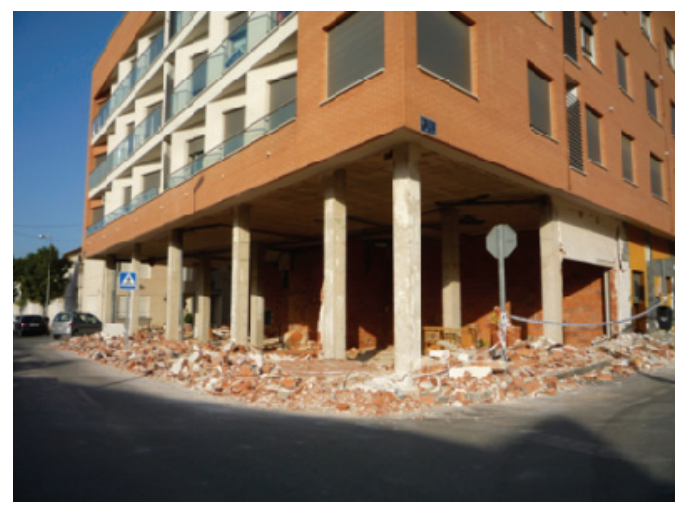

Fig. 6. Pérdida de los cerramientos por el efecto de planta blanda.

Tanto el Eurocódigo 8 como la Normativa de Construcción Sismorresistente Española (NCSE, 2002) consideran que los muros de relleno son elementos noestructurales; aun así, su contribución a la rigidez lateral de la estructura debería tomarse en cuenta a la hora de dimensionar los elementos estructurales. En el FEMA 454 (FEMA, 2006) se presentan algunas soluciones para prevenir el efecto de planta blanda en plantas bajas que se desean mantener abiertas. Estas soluciones incluyen aumentar el número de pilares, añadir refuerzo lateral o arbotantes externos que contribuyan a aumentar la rigidez de esa planta para igualarla a las demás. 

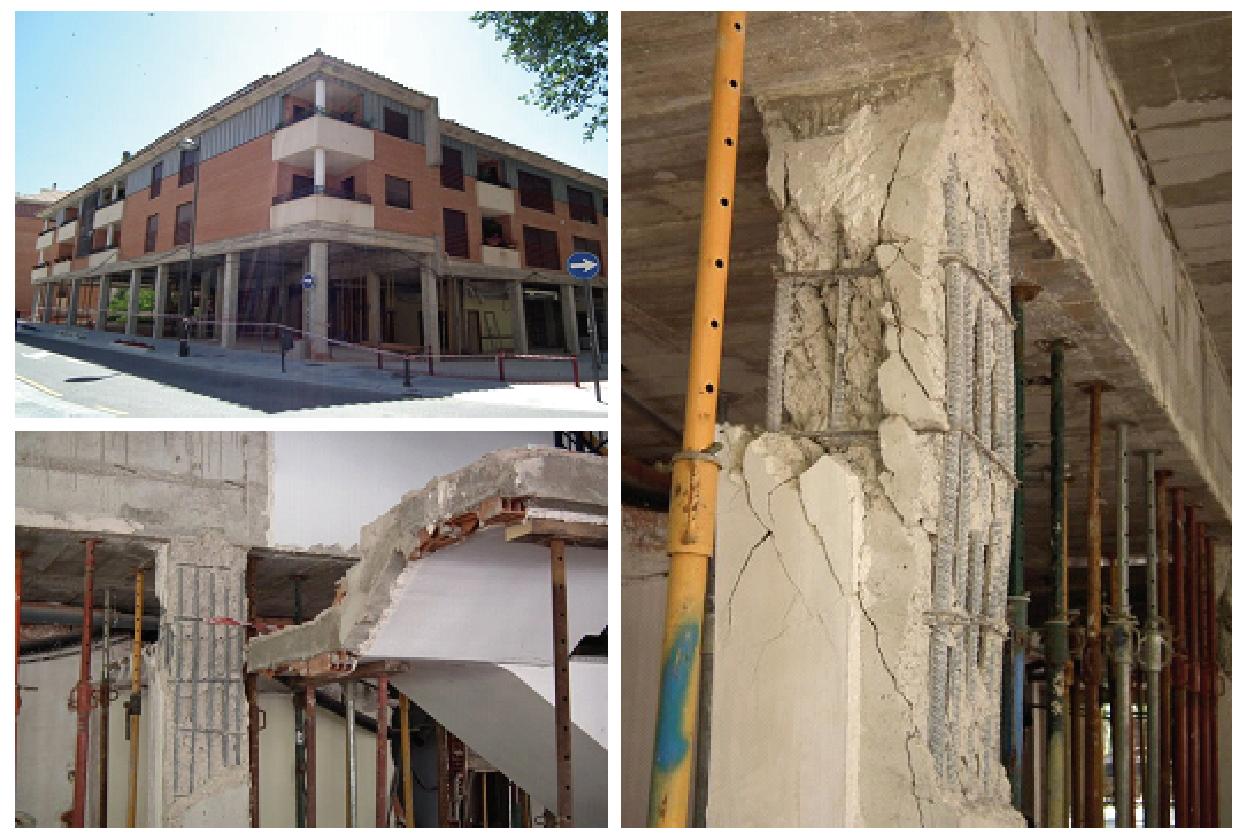

Fig. 7. Pérdida de cerramientos y daños a pilares en una planta blanda.

\subsubsection{Falta de confinamiento de los pilares}

La utilización de una armadura transversal inadecuada en los pilares -por ejemplo, un diámetro insuficiente del redondo y un espaciamiento inadecuado de los cercos o su mala conexión - impiden el confinamiento de dichos elementos, sobre todo en las zonas de los nudos, e influye decisivamente en el comportamiento sísmico de los edificios.

Se observaron muchos pilares dañados no sólo por los efectos anteriormente mencionados sino también por deficiencias en las armaduras de refuerzo, tanto longitudinales como transversales y en las uniones entre losas y pilares (Figura 8). Estas deficiencias incluyen el uso de acero no corrugado, excesiva distancia entre el refuerzo transversal y el pobre confinamiento de las armaduras. Dependiendo del año de construcción del edificio, estas características que llamamos "deficiencias" hoy en día, podrían haberse considerado normales y correctas en el momento de construirse el edificio. 

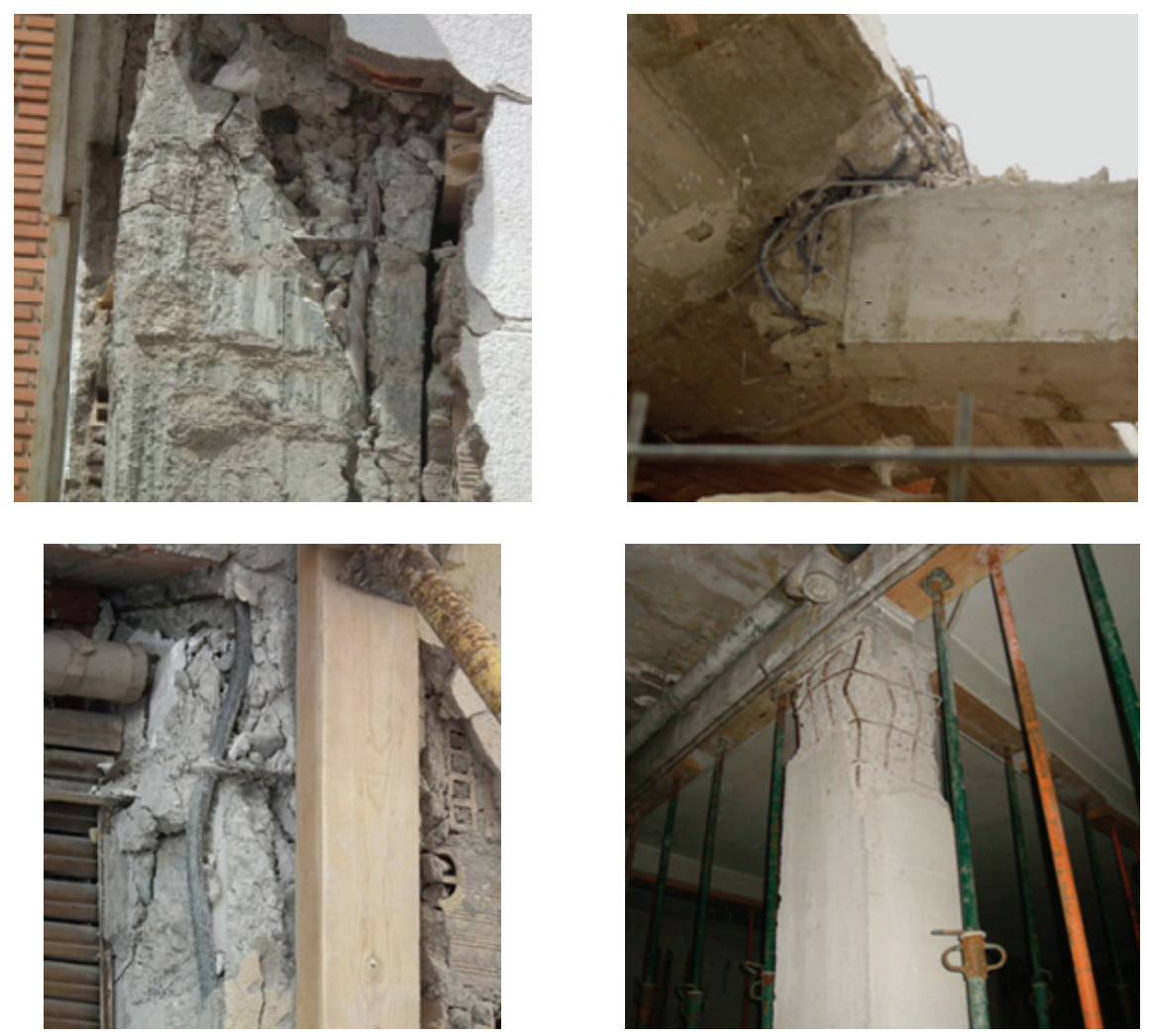

Fig. 8. Posibles deficiencias en las armaduras de refuerzo identificadas en Lorca.

\subsubsection{Efecto del golpeteo}

Cuando dos o más edificios adyacentes están muy cercanos la vibración de un terremoto fuerte puede hacer que estos se golpeen mutuamente (Figura 9). Si estos edificios son de diferente altura y sus plantas no coinciden, las plantas y el techo del edificio más bajo pueden golpear a media altura los pilares del edificio más alto, lo que puede causar importantes daños.

Durante la visita a Lorca se identificaron algunos casos de golpeteo como se muestra en la Figura 10. Los daños por golpeteo suceden porque el espacio que se deja entre los edificios es insuficiente para que los mismos puedan desplazarse lateralmente sin perjudicarse. 


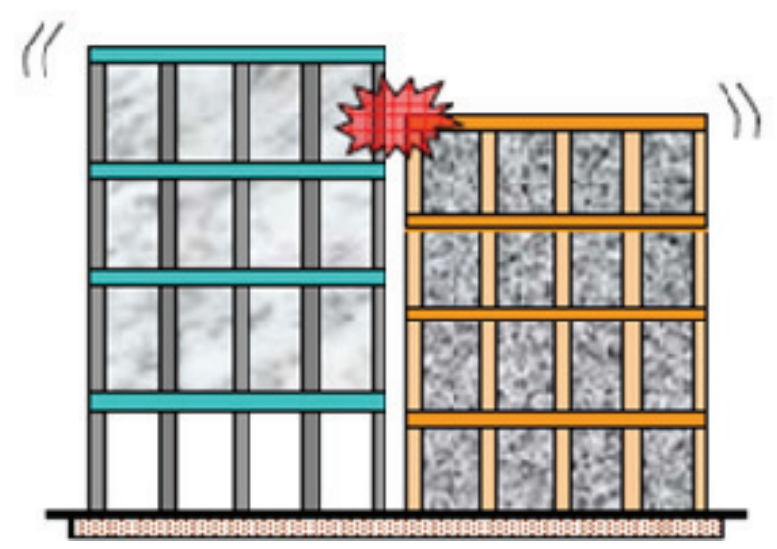

Fig. 9. Esquema del efecto de golpeteo entre dos edificios adyacentes de diferente altura (Murty, 2004)
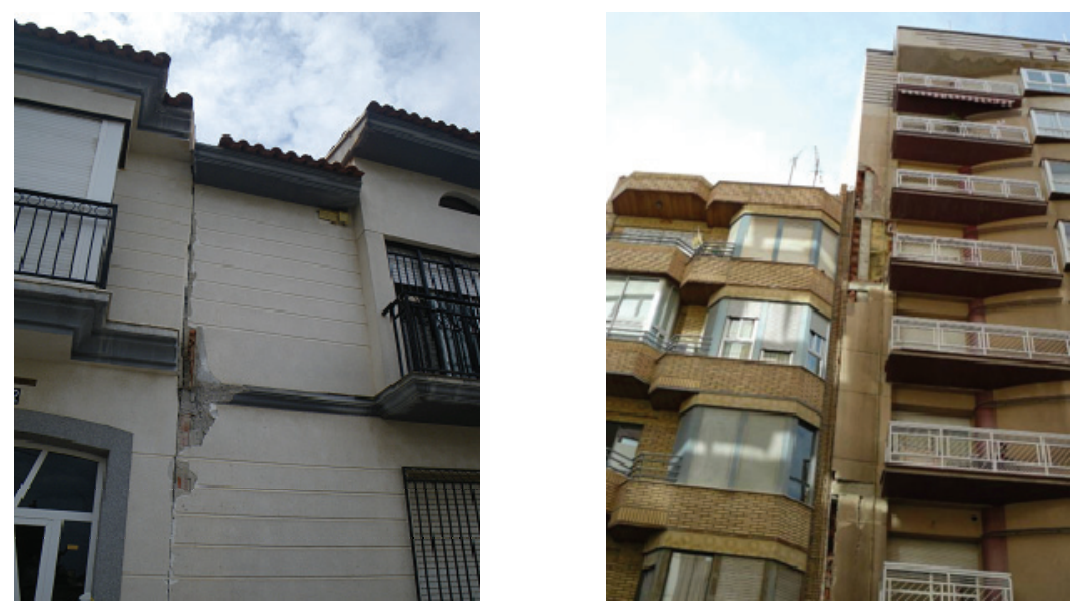

Fig. 10. Efectos del golpeteo observados en la visita post-terremoto a Lorca.

\subsection{Mampostería no reforzada}

La gran mayoría de los edificios de mampostería no reforzada de ladrillo o de piedra del centro de Lorca son antiguos y, obviamente, anteriores a las normas de diseño sismorresistente.

La acción sísmica degrada la conexión entre los elementos de fábrica que forman los muros y la eventual pérdida de conexión entre los propios muros. Al aumentar el grado de este daño, se puede alcanzar el colapso de uno o más muros, o incluso el de la estructura. Los daños observados en los edificios de mampostería no reforzada se presentan en la Figura 11 y la Figura 12. 
La Figura 11 muestra los daños en un edificio de mampostería no reforzada en aparente buen estado de conservación. Éste presenta agrietamiento local de sus muros debido a la acción de las cargas dinámicas producidas por el terremoto de Lorca. También se observan daños en las cornisas y en el dintel de la entrada principal.
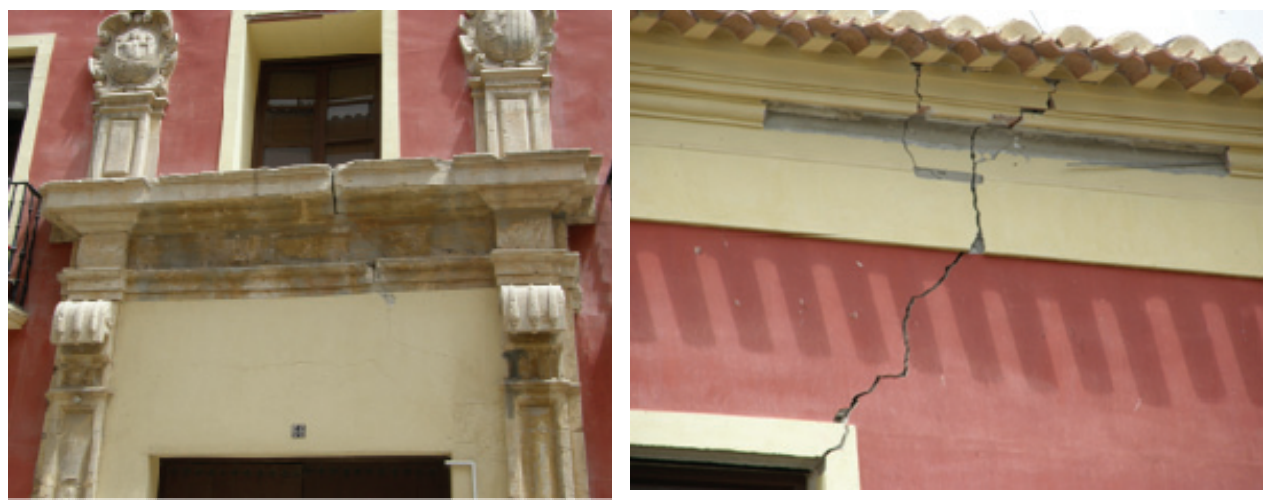

Fig. 11. Daños en las estructuras de mampostería no reforzada.

En la Figura 12 se muestran los daños a un edificio de mampostería no reforzada mucho más vulnerable que el anterior y en un estado de conservación deficiente. El mismo presenta daños importantes en parte de la fachada y de la cubierta, así como abundantes fisuras en sus muros.
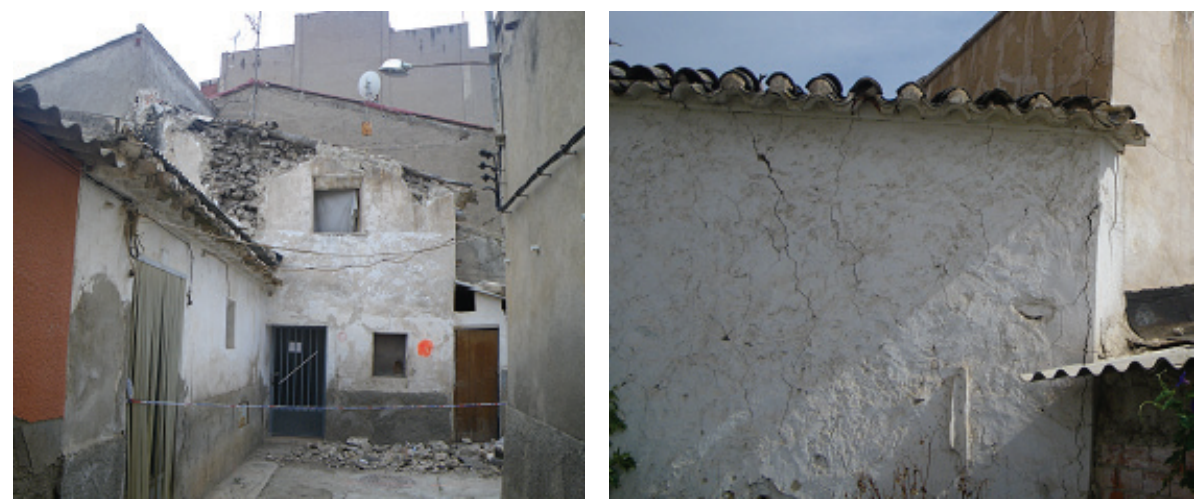

Fig. 12. Daños en las estructuras de mampostería no reforzada. 


\subsection{Edificios de autoconstrucción}

En las pedanías del municipio cercanas al centro de Lorca se observaron estructuras con mayor grado de daño. En estas zonas abundan las casas unifamiliares individuales que en su gran mayoría responden al fenómeno de la autoconstrucción. Son estructuras ejecutadas sin un cálculo de su resistencia y principalmente pensadas para soportar su propio peso. Muchas de estas casas presentan estructuras mixtas, haciendo mucho más complejo su comportamiento sísmico.

La Figura 13 muestra algunas estructuras con daños en la pedanía de Diputación de Río del municipio de Lorca. Los daños más frecuentes incluían muros de mampostería con múltiples grietas, desplazamiento y caída de los tejados, así como el desplazamiento de fachadas entre otros.

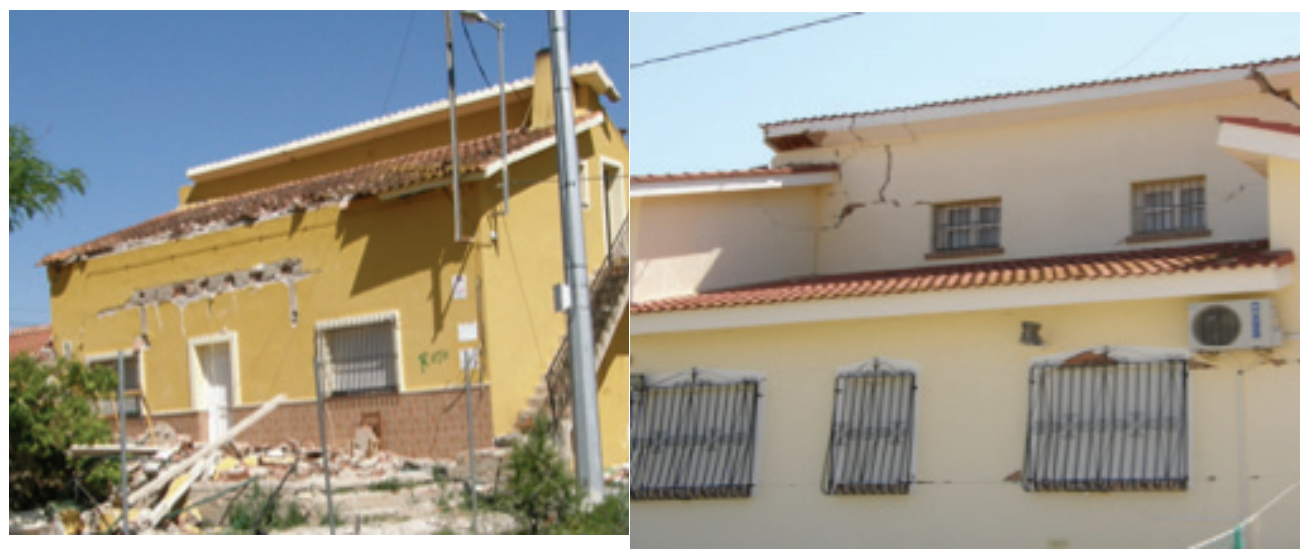

Fig. 13. Daños en viviendas unifamiliares en la pedanía de Diputación de Río en el municipio de Lorca

\section{Daños en elementos no estructurales}

Se han encontrado numerosos daños en elementos no estructurales, los cuales fueron responsables del fallecimiento de la mayoría de las nueve víctimas que dejó el terremoto en Lorca. La norma vigente no fija límites de deformación lateral de los edificios que permitan minimizar los daños no estructurales, por este motivo, en muchos casos de edificios de hormigón armado, cuya estructura no ha sufrido daños o ha sufrido daños menores durante sismos, los cerramientos o tabiques pueden sufrir grandes daños. La falta de conexión entre los paneles de fábrica y la estructura hace que dichos elementos se dañen tanto por movimientos fuera de plano como por movimientos en el plano. Además de las víctimas humanas, las pérdidas económicas por esta causa pueden ser cuantiosas a nivel de una ciudad entera.

Los elementos no estructurales con el borde superior libre, como cornisas, antepechos, parapetos y chimeneas, deben enlazarse a la estructura, tal como lo requiere 
la norma sismorresistente NCSE-02, algunas veces mediante un encadenado de coronación, para garantizar su estabilidad.

Se observaron parapetos de ladrillo no reforzados (Figura 14) que colapsaron cayendo sobre edificios contiguos o sobre la calle y chimeneas dañadas en casas residenciales unifamiliares (Figura 15).

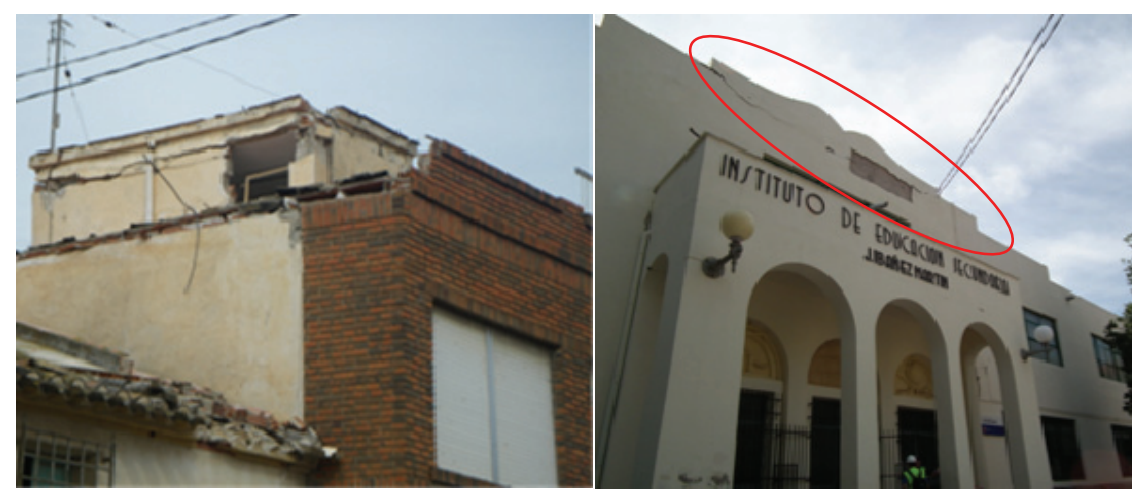

Fig. 14. Elementos no estructurales no anclados a la estructura.

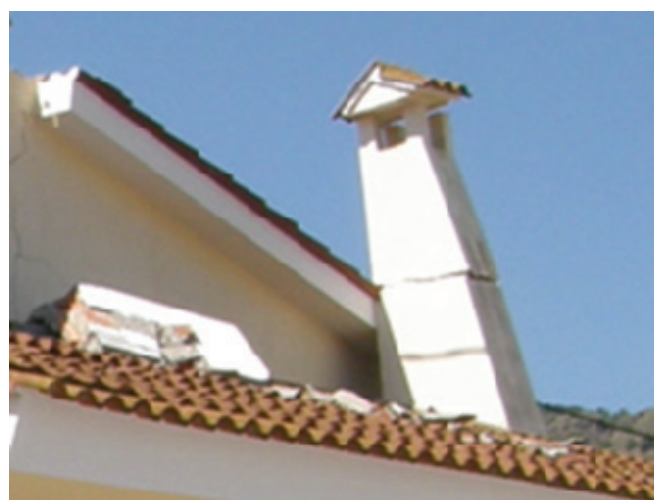

Fig. 15. Chimenea dañada por el terremoto en casa residencial

También se observaron daños en cajas de escaleras y ascensores (Orona-Pecrès, 2011), los cuales se presentaron principalmente en las plantas bajas y en las primeras plantas de los edificios, que debido a las mayores cargas de flexión/compresión han sido las más dañadas. En su mayoría se trata de derribos de los cerramientos de 
los huecos de ascensor, generalmente de ladrillo, como los que se observan en la Figura 16.

Las puertas exteriores de los ascensores en las plantas a nivel de calle han sufrido deformaciones por cargas de compresión y flexión, según la situación de éstas en el edificio (Figura 17).

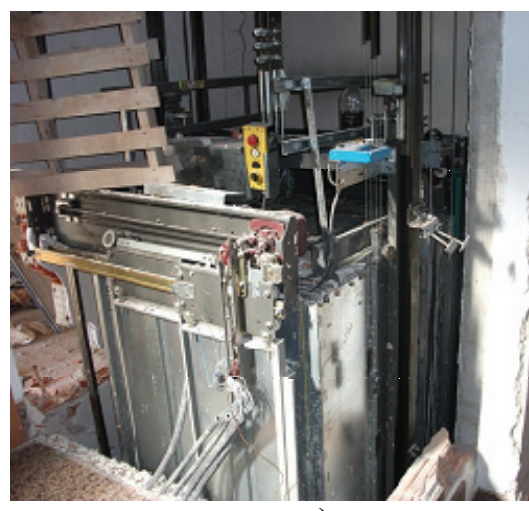

a)

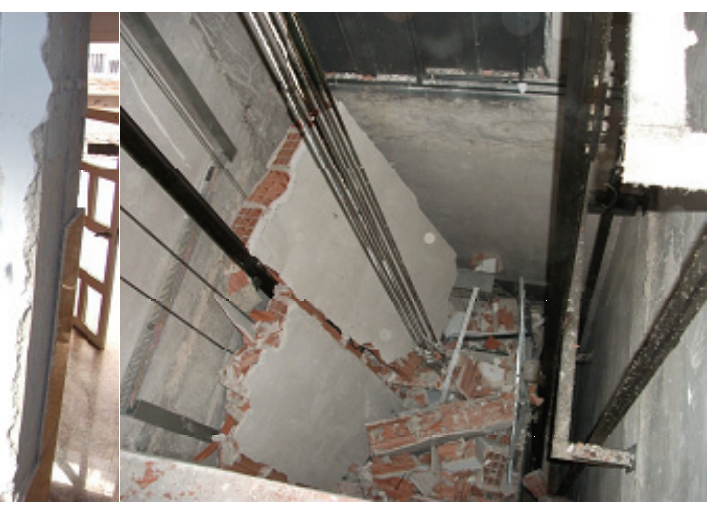

b)

Fig. 16. a) Vista de cabina desde el exterior por cerramientos derribados b) Cerramiento de ladrillo derribado sobre el techo de la cabina del ascensor.

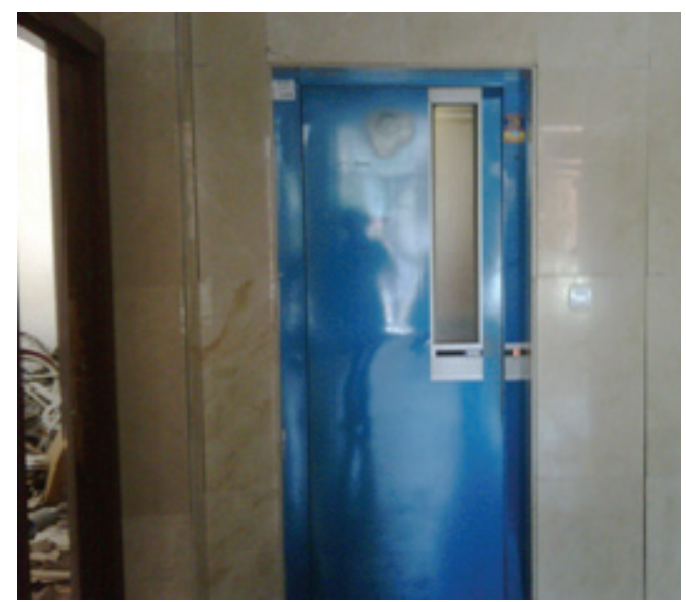

Fig. 17. Puerta de ascensor deformada por cargas de compresión

Este tipo de patologías se ha presentado en el $80 \%$ de las instalaciones existentes en la zona afectada, siendo los daños de diversa gravedad en función de la afectación de la estructura y cerramientos. Cabe destacar que restablecer el servicio de los 
ascensores depende en muchos casos de las reparaciones estructurales y de albañilería (Orona-Pecrès, 2011).

Se observaron algunos aparatos de aire acondicionado que quedaron suspendidos del cableado al desprenderse la fachada a la que estaba anclada su estructura metálica de sujeción (Figura 18).
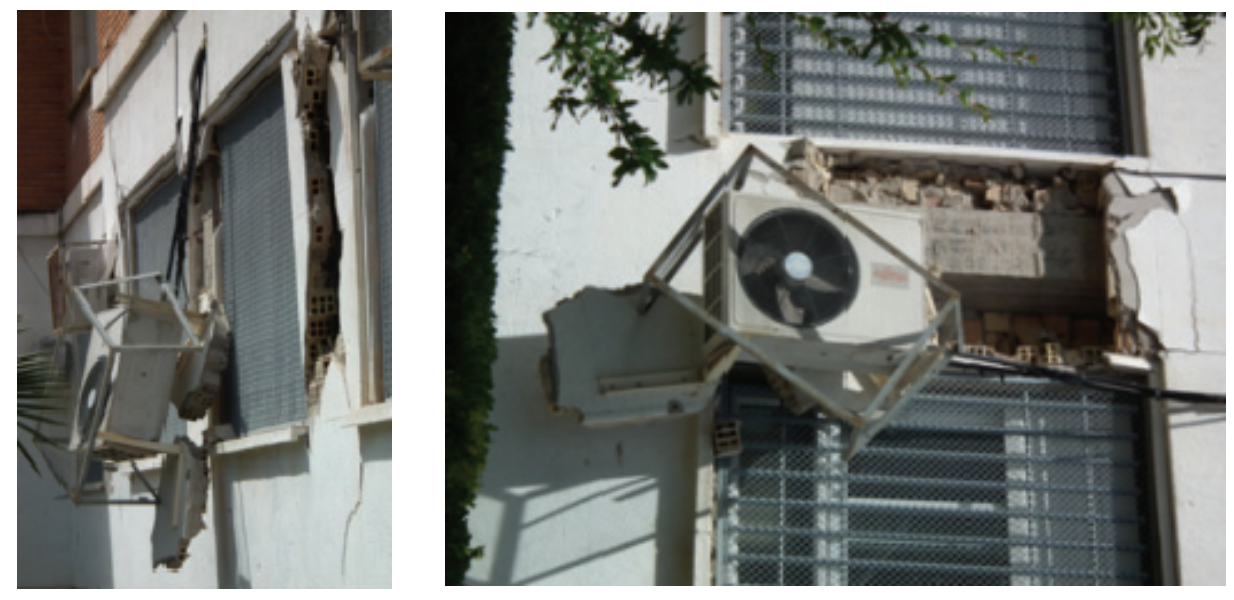

Fig. 18. Aparatos de aire acondicionado anclados a la fachada, después del terremoto.

\section{Daños en el patrimonio cultural y religioso}

Los monumentos de Lorca se han visto seriamente afectados por el terremoto del 11 de mayo. Pasadas 3 semanas del terremoto, la Consejería Cultural de Lorca valoraba en 50 millones de euros los daños que se habían producido en el patrimonio histórico, en un total de 29 monumentos de Lorca (La Verdad, 2011a). Entre estos monumentos dañados se encuentran numerosas iglesias, el museo arqueológico, la plaza de toros, el castillo de Lorca, el Palacio Guevara y el monasterio de las Clarisas.

La mayoría de los monumentos afectados son iglesias que tienden a ser de las tipologías más vulnerables a las acciones sísmicas (Lagomarsino et al., 2004). De las 13 iglesias más importantes y de mayor valor patrimonial del centro de Lorca sólo 2 se encontraban en condiciones de seguir abiertas el público después del terremoto, mientras que las restantes presentaban daños importantes tanto estructurales como no estructurales.

Entre los daños observados en los monumentos de Lorca se encuentran la rotura y/o colapso de cúpulas, torres o campanarios, agrietamiento y desplazamiento de arcos, pilares, contrafuertes, agrietamiento y/o colapso de muros. 


\subsection{Iglesia de Santiago}

Una de las más afectadas fue la iglesia de Santiago. Construida en el siglo XV, sufrió daños durante el terremoto de 1674; se reconstruyó en 1781 y luego se vio afectada por varios incendios y por la Guerra Civil. En 1940 se comenzó un nuevo proceso de reconstrucción que incluyó la edificación del campanario. Desde afuera sólo se observaron daños importantes en su campanario (Figura 19). No obstante, esta iglesia ha quedado prácticamente en ruinas tras el terremoto. En el interior se observa el colapso del crucero y de la cúpula. Los muros y la parte restante de la cubierta se encuentran muy afectados por la acción sísmica (Figura 20).

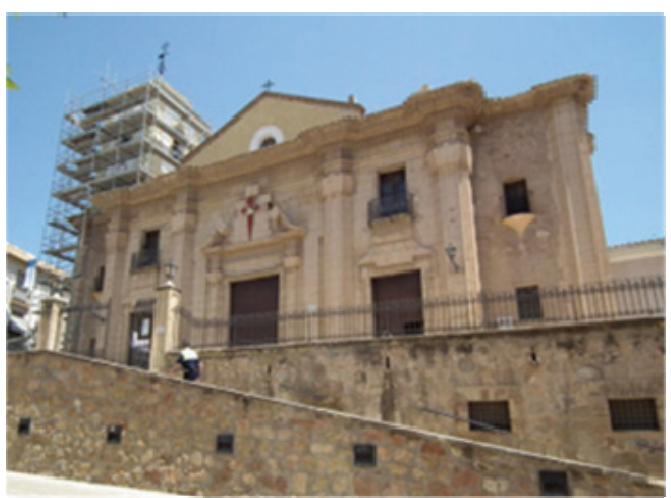

a)

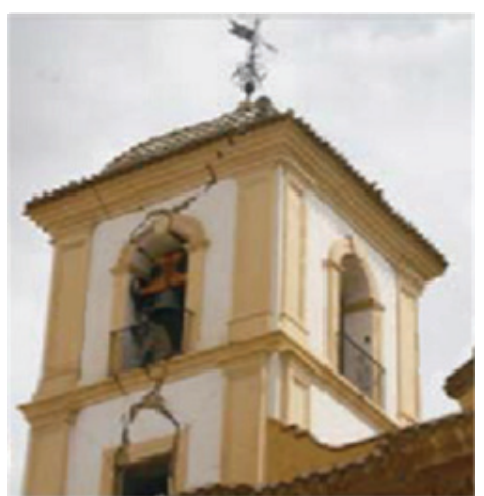

b)

Fig. 19. a) Fachada de la iglesia de Santiago y daños en su torre. b) torre del campanario pocos días después del terremoto (IGME, 2011)

\subsection{Iglesia del Carmen}

El convento y la Iglesia del Carmen se construyeron durante el S. XVIII. La Iglesia del Carmen ha quedado totalmente inutilizada y con riesgo de derrumbe a causa del terremoto. La iglesia tiene planta basilical, de tres naves y coro alto a los pies, en el cual se pueden ver los daños producidos por el terremoto (Figura 21a). También se observaron daños en los arcos situados bajo la cúpula levantada sobre un anillo ondulante (Figura 21b). 


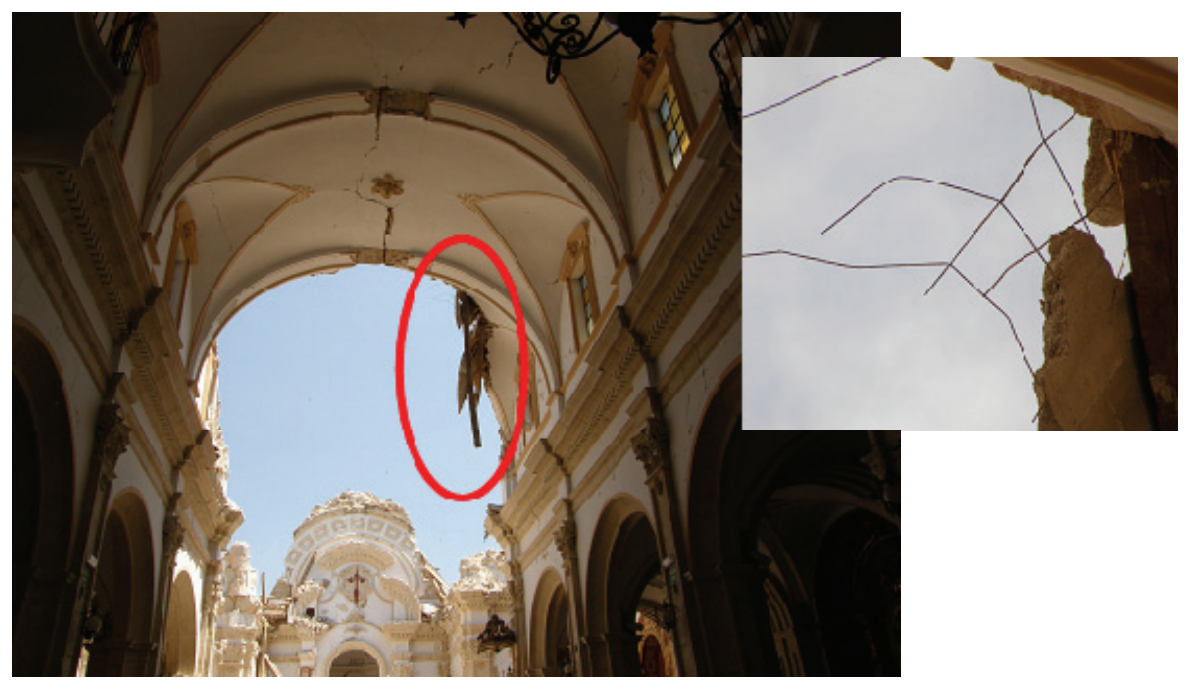

Fig. 20. Colapso de la cúpula y del crucero de la iglesia de Santiago y detalle de mallas de refuerzo

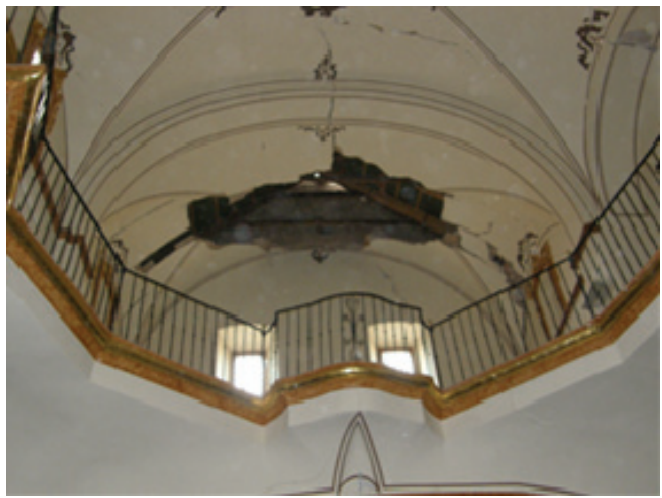

a)

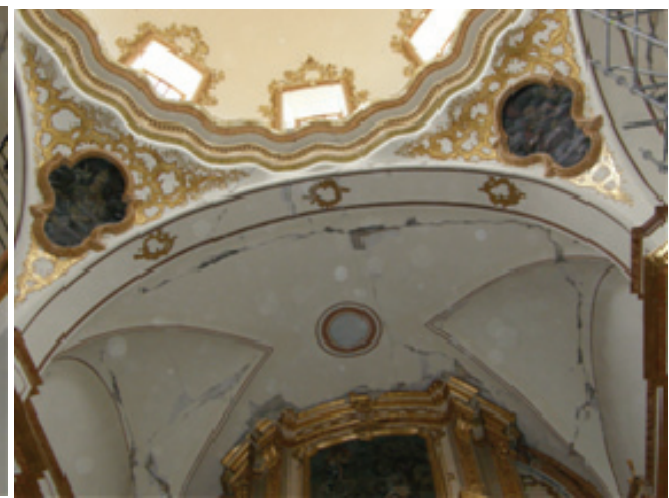

b)

Fig. 21. Daños en el coro y arcos bajo la cúpula de la Iglesia del Carmen

Su fachada pantalla está formada por dos cuerpos y coronada por frontón. En el cuerpo inferior se abren tres vanos en forma de arco de triunfo abocinados que se corresponden con las tres naves de la iglesia. Los daños en la fachada se aprecian en el vano central, que es el de mayor altura y ligeramente más amplio que los laterales, en correspondencia también con la altura de las naves. En la Figura 22 pueden observarse los daños en la clave de las ventanas bajo el frontón curvilíneo que remata la fachada. 


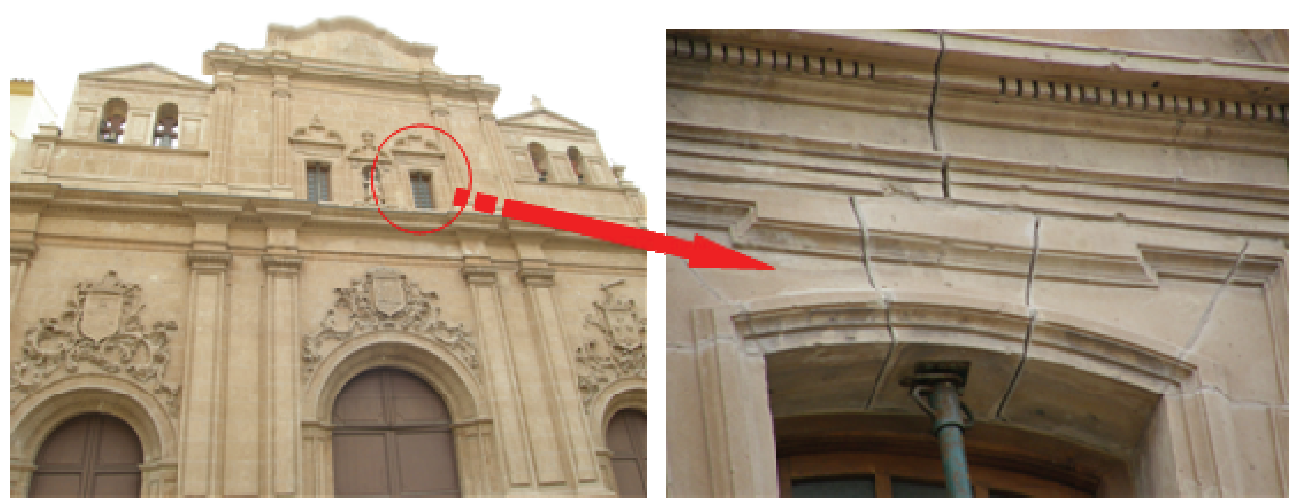

Fig. 22. Daños en el arco de la fachada de la Iglesia del Carmen

\section{Daños en edificios de importancia especial}

El terremoto de Lorca del 11 de mayo de 2011 es una nueva llamada de atención sobre la gestión de la seguridad de edificios de importancia especial como instalaciones de salud y centros educativos frente al peligro sísmico.

La gestión de la seguridad de dichos edificios implica la evaluación de riesgos, el diseño de planes de mitigación fundamentados en relaciones de beneficio-costo, así como la financiación y ejecución de tales actividades. Un esquema de programas continuos de reducción de la vulnerabilidad de centros educativos y de hospitales se encuentra en los documentos FEMA 395 (2003) y FEMA 396 (2003) respectivamente.

\subsection{Centros de enseñanza}

De los 17 Centros de Educación Infantil y Primaria y los 8 Institutos de Educación Secundaria, identificados en Lorca, un total de 10 centros sufrieron daños que limitaron su ocupación. Las clases se reactivaron en un periodo de entre 5 y 12 días. Cerca de 6.600 alumnos de los centros que han sido clasificados por la comisión de evaluación de daños como de uso restringido fueron trasladados a otros centros ( $\mathrm{La}$ Vanguardia 13/05/2011).

En los 3 centros de enseñanza inspeccionados se han observado daños estructurales y no estructurales considerables. En los edificios de hormigón armado se han identificado daños graves en pilares y en muros de fachada y divisorios. En el caso de edificios de muros de fábrica se han observado daños considerables tanto en los muros perimetrales como en los divisorios.

En algunos de los centros que no han sufrido daños estructurales, se observaron daños no estructurales fuertes y severos que limitaron la ocupación del edificio. Debe prestarse especial atención a este tipo de daños ya que pueden causar lesiones en los niños, así como dificultar en muchos casos la salida del edificio por obstaculizar las escaleras o la apertura de puertas. 
La reparación de los centros educativos afectados debe superar el alcance de una solución temporal de la emergencia y orientarse a la rehabilitación de los equipamientos para que cumplan los estándares de seguridad exigidos para edificios de importancia especial. Así mismo, los daños observados deben motivar el desarrollo de programas regionales/nacionales de reducción de la vulnerabilidad estructural y no estructural de los centros educativos para garantizar la seguridad de los estudiantes y de las inversiones realizadas.

\subsection{Edificios de salud}

En el municipio de Lorca, los equipamientos de salud están conformados por el Hospital Rafael Méndez y varios centros de salud. El Hospital Rafael Méndez es el de referencia para La Gerencia III de Salud (Lorca) y cuenta con 280 camas. En este hospital, la media diaria de emergencias en situaciones normales, es de 170 (Consejería de Sanidad y Consumo 2011a).

Algunas de las instalaciones de servicios médicos perdieron su funcionalidad debido a su vulnerabilidad no estructural. Este hecho debe motivar a los encargados del servicio de salud a evaluar la vulnerabilidad y el riesgo de las instalaciones de la región, considerando aspectos estructurales, no estructurales y de capacidad de respuesta a la emergencia. Al respecto, se considera que el Índice de Riesgo de Hospitales sugerido en Valcárcel et al. (2011) puede ser una herramienta útil para la definición de medidas preventivas y correctivas, orientadas a garantizar la seguridad de los servicios médicos y de sus usuarios. En la Tabla 1 se presenta un resumen de los daños encontrados después del evento.

Tabla 1. Resumen de daños en los edificios de salud del municipio de Lorca

\begin{tabular}{|l|l|}
\hline Equipamiento & \multicolumn{1}{|c|}{ Resumen de daños } \\
\hline $\begin{array}{l}\text { Hospital } \\
\text { dez }\end{array}$ & $\begin{array}{l}\text { Sin daños estructurales. Daños en falsos techos y en algunos muros diviso- } \\
\text { rios. Varios servicios quedaron inhabilitados. }\end{array}$ \\
\hline $\begin{array}{l}\text { Centro de } \\
\text { Salud Lorca } \\
\text { Centro }\end{array}$ & $\begin{array}{l}\text { Sufrió importantes daños estructurales. Su actividad se trasladó a Santa } \\
\text { Rosa de Lima*. Se resalta que estaba previsto demoler el edificio y reem- } \\
\text { plazarlo con una nueva construcción de } 3000 \mathrm{~m}^{2} \text {, cuyo valor sería cercano a } \\
4,8 \text { millones de euros y cuyo equipamiento podría costar } 500.000 € \text { (La } \\
\text { Verdad 2011b). }\end{array}$ \\
\hline $\begin{array}{l}\text { Centro de } \\
\text { Salud Lorca } \\
\text { San Diego }\end{array}$ & $\begin{array}{l}\text { Presentó daños no estructurales. La reactivación de sus servicios se estimó } \\
\text { que tardaría una semana*. }\end{array}$ \\
\hline $\begin{array}{l}\text { Centro de } \\
\text { Salud Lorca } \\
\text { Sur }\end{array}$ & $\begin{array}{l}\text { Presentó daños no estructurales. Edificio con restricción de ocupación. La } \\
\text { asistencia sanitaria se traslado al centro de Salud Mental*. }\end{array}$ \\
\hline
\end{tabular}




\subsubsection{Hospital Rafael Méndez}

El hospital tiene una estructura modular compuesta. El edificio original fue inaugurado en 1990 y su estructura es de pilares y forjados de hormigón armado. La instalación fue ampliada con una estructura de pórticos de acero con cerramientos con muros de fábrica. El edificio tiene cuatro plantas sobre rasante y es irregular en planta y en altura. Está ubicado en terreno con pendiente. Entre las reformas que se han realizado al edificio, se encuentra la construcción de contrafuertes para garantizar su estabilidad.

Los daños estructurales en el hospital fueron entre nulos y leves. No se identificaron fisuras significativas en pilares y forjados en la estructura original, ni tampoco deformaciones apreciables en los pórticos metálicos. En las juntas de dilatación de la estructura se encontraron desplazamientos que no representan daños estructurales considerables (Figura 23).

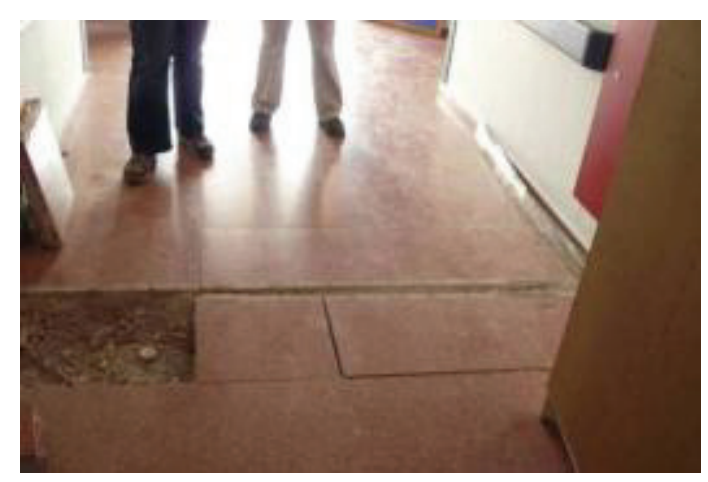

Fig. 23. Desplazamientos de la junta de dilatación

A pesar de que los daños estructurales fueron nulos y leves, se produjeron daños severos en elementos no estructurales que limitaron la funcionalidad del hospital. La instalación fue evacuada por consenso de los responsables del hospital y sus pacientes fueron transferidos a otros centros del Servicio Murciano de Salud. En la mayoría de los muros de fachada se encontraron daños entre nulos y leves. Se identificaron pocas zonas con daños entre graves y severos con agrietamientos y desprendimiento de los elementos de recubrimiento (Figura 24). Los daños observados en los muros internos son entre leves y moderados; no se identificaron zonas con agrietamientos considerables. En los muros de la escalera se presentaron fisuras que fueron reparadas rápidamente. También se presentaron fallas puntuales en las ventanas de la instalación (Figura 25a). Respecto a los falsos techos, en algunas zonas del hospital los daños observados varían entre fuertes y severos (Figura 25b). 

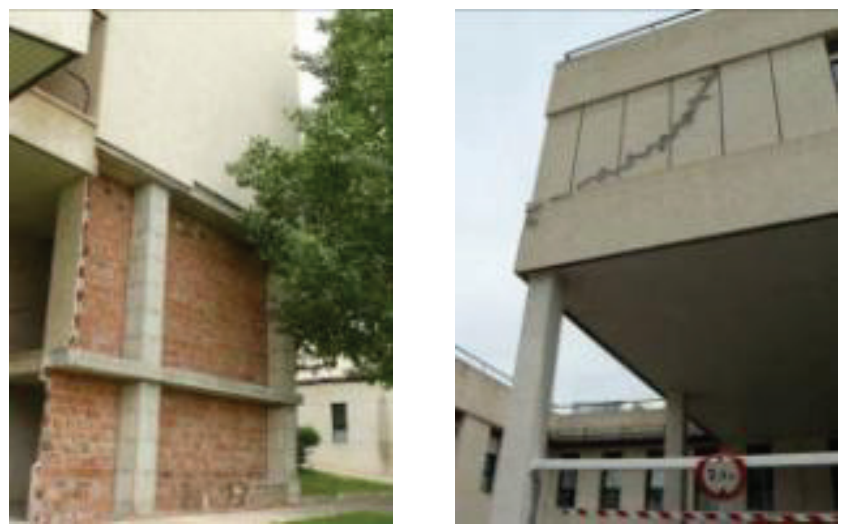

Fig. 24. a) Colapso de muros de fachada; b) fisuras en muro de fachada

Durante la inspección no se identificaron zonas obstaculizadas por estanterías y elementos de mobiliario y oficina. No obstante, se observó que pocos se encuentran anclados a los muros o al suelo. Así mismo, pocos cuentan con protecciones que sujeten e impidan la caída de los contenidos, tal como se sugiere en el manual del evaluador del Índice de Seguridad de Hospitales (WHO 2008) y en las indicaciones para la rehabilitación sísmica de hospitales (FEMA 396).

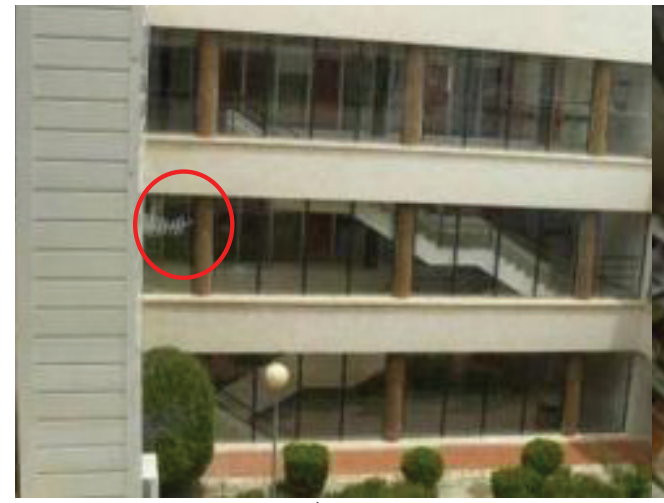

a)

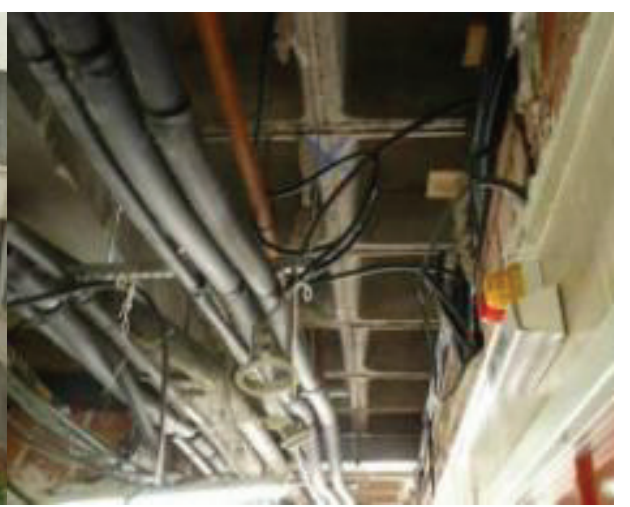

b)

Fig. 25. a) Rotura de ventanas; b) daños en falso techo

Por otro lado, el equipamiento médico del Servicio de Urgencias, Radiología y su laboratorio así como el de Anatomía Patológica y Diálisis no sufrió daños (Consejería de Sanidad y Consumo 2011a). En los quirófanos, se observó que la mesa de operaciones cuenta con un soporte anclado al suelo y el equipo auxiliar se encuentra 
sobre mesas rodantes. En uno de los quirófanos se observó un ligero agrietamiento en la conexión de la lámpara al techo (Figura 26).

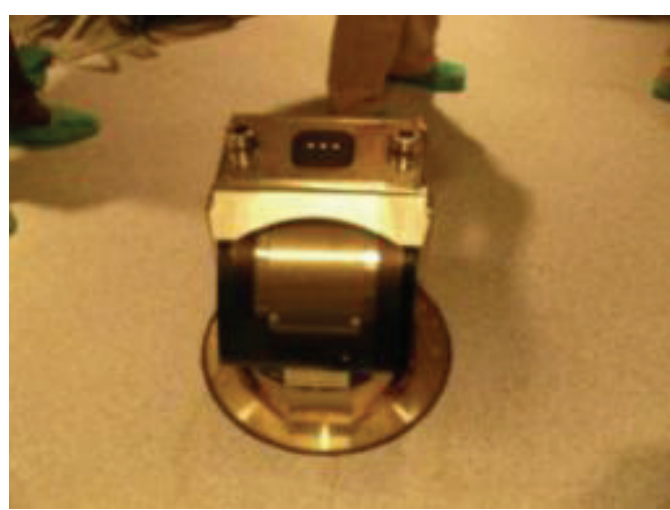

a)

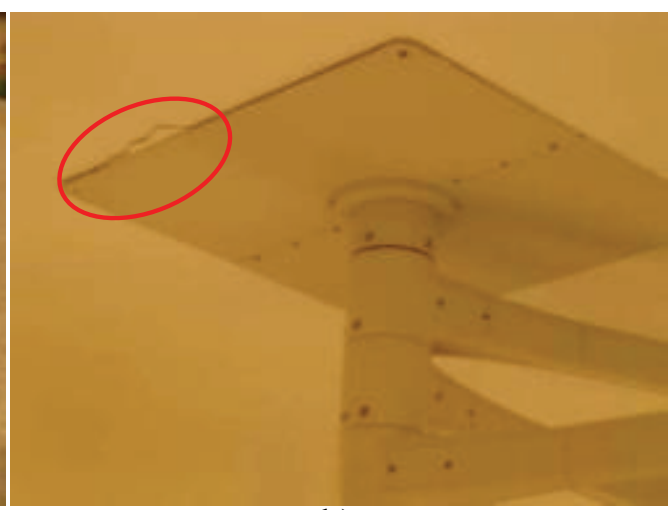

b)

Fig. 26. a) Anclaje de la mesa de operaciones; b) conexión de la lámpara de los quirófanos

En cuanto a la sala de radiología, se informó que sobre estos equipos se realiza mantenimiento periódico. Estos elementos se encuentran anclados al techo o a la pared.

\section{Lecciones aprendidas}

A continuación se hacen algunas observaciones referentes al comportamiento de los edificios durante el terremoto de Lorca.

- Es más eficiente realizar la evaluación post-sísmica de daños por inspectores con experiencia o entrenados en el uso de formularios de evaluación durante el período que transcurre entre dos terremotos.

- Como no es razonable prever ningún cambio en las tipologías estructurales que se utilizan en España, es importante aprender a convivir con las existentes y mejorar su comportamiento sísmico.

- Proyectar un edificio en una zona sísmica a partir de una configuración estructural con errores, como los que se han descrito en este informe, puede conducir a un comportamiento sísmico inadecuado, incluso si los cálculos y el armado se hacen de acuerdo con las normas. Como dichos errores de configuración caen dentro de las prácticas habituales de proyecto y construcción y, previsiblemente, se seguirán cometiendo, debe encontrarse la forma de mejorar la seguridad sísmica de los edificios teniendo en cuenta este factor condicionante ("improving errors"!).

- En los edificios de nuevo diseño es recomendable evitar el uso de pilares cortos y, si es imposible evitarlos, deben dimensionarse considerando este efecto. 
- El terremoto de Lorca no ha producido ningún tipo de daño estructural y no estructural inesperado, es decir, que no se haya producido, estudiado y catalogado en estructuras similares de otras zonas sísmicas de Europa y del resto del mundo durante los terremotos ocurridos en el pasado.

- Errores similares de configuración conducen a daños y a pérdidas por sismo similares en diferentes zonas sísmicas.

- Los elementos no estructurales pueden dañarse incluso cuando la estructura de hormigón armado tiene un comportamiento elástico durante un terremoto. En este sentido, se puede afirmar que la mayoría de los edificios más recientes de Lorca sufrieron únicamente daños no estructurales. Debe recalcarse que este efecto puede producir pérdidas humanas y económicas importantes.

- La reparación de estructuras dañadas por terremotos debe llevarse a cabo después de que los especialistas hayan realizado un estudio específico que establezca el estado post-sísmico del edificio y su proyecto de reparación.

- Los edificios monumentales de mampostería reparados o reforzados en los años 60 utilizando hormigón armado no suelen tener el comportamiento sísmico mejorado previsto en su momento.

- En los edificios esenciales y de importancia especial, deben evitarse no sólo los daños estructurales sino también los no estructurales, así como los daños en las instalaciones, a fin de garantizar permanentemente el cumplimiento de sus funciones.

\section{Agradecimientos}

Queremos agradecer la colaboración de todas las personas y organismos que facilitaron y participaron en la realización de la inspección técnica. En particular los siguientes organismos:

- Instituto Geográfico Nacional (IGN)

- Policía Municipal de Lorca

- Asociación Francesa de Ingeniería Sísmica (AFPS)

- Asociación Portuguesa de Ingeniería Sísmica (SPES)

Los autores agradecen también el apoyo del Ministerio de Educación y Ciencia de España, proyecto "Enfoque integral y probabilista para la evaluación del riesgo sísmico en España"-CoPASRE (CGL2011-29063), y de la Comisión Europea proyecto DESURBS-FP7-2011-261652.

\section{Referencias bibliográficas}

AFPS (2011). Le séisme de Lorca du 11 Mai 2011. Rapport de mission. Décembre 2011

AYUNTAMIENTO DE LORCA (2012). Visor geográfico del seismo de Lorca. Disponible en: http://www.lorca.es/seismo11demayo/seismo11demayo.asp? id=1540 [Última consulta 26/04/2012]

BARBAT, A.H., CARREÑO, M.L., FIGUERAS, S., GOULA, X., IRIZARRY, J., LANTADA, N.; MACAU, A. \& VALCÁRCEL, J. (2011). El Terremoto de 
Lorca del 11 de mayo de 2011. Informe de la inspección y de los trabajos de campo realizados. Monografía técnica $\mathrm{N}^{0} 3$, Institut Geològic de Catalunya. Barcelona, España. Disponible en: http://www.igc.cat/web/files/igc_mt_03_lorca.pdf

CREM (2012). Centro Regional de Estadística de Murcia http://www.carm.es/ [Última consulta 13/03/2012]

CONSEJERÍA DE SANIDAD Y CONSUMO (2011a). "El Servicio de Urgencias del Hospital Rafael Méndez de Lorca ya está operativo" Consejería de Sanidad y Consumo - [13/05/2011]. Disponible en: http://www.murciasalud.es/noticias.php?op=ver\&id=209070\&idsec=66 [Última consulta 03/06/2011]

CONSEJERÍA DE SANIDAD Y CONSUMO (2011b). "Sanidad reorganiza los servicios de Atención Primaria del municipio de Lorca" Consejería de Sanidad y Consumo - [13/05/2011]. Disponible en: http://www.murciasalud.es/noticias.php?op=ver\&id=209154\&idsec $=66 \quad$ [Última consulta 03/06/2011]

CONSEJERÍA DE SANIDAD Y CONSUMO (2011c). "El Servicio de Urgencias del Hospital Rafael Méndez de Lorca ya está operativo" Consejería de Sanidad y Consumo - [13/05/2011]. Disponible en: http://www.murciasalud.es/noticias.php?op=ver\&id=209070\&idsec $=66$ [Última consulta 03/06/2011]

CONSEJERÍA DE SANIDAD Y CONSUMO (2011d). "Sanidad reorganiza los servicios de Atención Primaria del municipio de Lorca" Consejería de Sanidad y Consumo - [14/05/2011]. Disponible en: http://www.murciasalud.es/noticias.php?op=ver\&id=209155\&idsec=66 [Última consulta $03 / 06 / 2011]$

FEMA 395 (2003). "Incremental seismic rehabilitation of school buildings (K-12) Providing protection to people and buildings". Risk Management Series. [En línea]. Disponible en: http://www.fema.gov/library/viewRecord.do?id=1980. [Última consulta 14/06/2011]

FEMA 396 (2003). "Incremental seismic rehabilitation of Hospital buildings Providing protection to people and buildings". Risk Management Series. [en línea]. Disponible en: http://www.fema.gov/library/viewRecord.do?id=1981. [Última consulta 14/06/2011]

FEMA 454, (2006). "Designing for Earthquakes, a manual for architects, Risk Management Series", Report No. FEMA-454, Federal Emergency Management Agency, December.

IGME (2011). Informe geológico preliminar del terremoto de Lorca del 11 de mayo del año 2011, 5.1 Mw. Instituto Geológico y Minero de España (IGME), Grupo de Tectónica Activa, Paleosismicidad y Riesgos Asociados de la Universidad Complutense de Madrid (UCM), Universidad Autónoma de Madrid (UAM) y la Universidad Rey Juan Carlos de Madrid (URJC)

IGN (2011). Serie terremoto NE Lorca, 11 mayo 2011. http://www.ign.es/ign/ resources/sismologia/Lorca.pdf 
INE (2012). Instituto Nacional de Estadística. Censo de edificios de viviendas de 2001.http://www.ine.es/censo_accesible/es/listatablas.jsp?table=tablas/provincia 1/30/E5.html. [Última consulta 28/03/2012]

LAGOMARSINO, S., PODESTÀ, S. \& RESEMINI, S. (2004). "Observational and mechanical models for the vulnerability assessment of monumental buildings". Proceedings of the 13th World Conference on Earthquake Engineering, Vancouver, B.C., Canada, Paper No. 942

LA VERDAD (2011a). Historia herida, noticia publicada en el periódico La Verdad, 29 de mayo de $2011 \mathrm{http} / / \mathrm{www}$. laverdad.es/murcia/v/ 20110529/cultura/ historia-herida-20110529.html. [Última consulta 10/07/2011]

LA VERDAD (2011b). El Centro de Salud Lorca Centro será demolido antes de finales de año [En línea]. Disponible en: http://www.laverdad.es/murcia/v/ 20110511/lorca/centro-salud-lorca-centro-20110511.html. [Última consulta $14 / 06 / 2011]$

LA VERDAD (2011c). Vistas aéreas después del terremoto de Lorca [En línea]. http://www.laverdad.es/murcia/multimedia/fotos/ultimos/77132-vistas-aereaslorca-despues-terremoto-0.html. [Última consulta10/07/2011].

MURPHY, P. (2011). Quick field report: Lorca Earthquake 11th May 2011, http://www.emsc-

csem.org/Files/event/221132/lorca_quickfieldreport_lowres.pdf [Última consulta $15 / 07 / 2011]$

MURTY, C.V. R. (2004). "How Architectural Features affect Buildings during Earthquakes?", "Indian Institute of Technology Kanpur - BMTPC Earthquake Tip 6", January 2004, http://www.iitk.ac.in/nicee/EQTips/EQTip06.pdf [Última consulta 16/04/2012]

NCSE (2002). "Normativa de Construcción Sismorresistente Española. Comisión Permanente de Normas Sismorresistentes“, Real Decreto 997/2002. Boletín Oficial del Estado No. 244 del 11 de octubre de 2002, España.

ORONA-PECRÈS (2011). Informe técnico: patologías en ascensores afectados por terremoto.

SALAZAR, A. (2011). Comunicación personal

VALCÁRCEL, J.A., PUJADES, L.G., MORA, M.G., BARBAT, A.H. \& CARDONA, O.D (2011). "Evaluación integrada de la seguridad de hospitales: implicaciones en la resiliencia de las comunidades". Revista Internacional de Ingeniería de Estructuras. Vol. 16, 1, 68-91 [En línea]. Disponible en: http://www3.espe.edu.ec:8700/handle/21000/2988 [Última consulta 14/06/2011]

WHO (2008). Índice de seguridad hospitalaria: Guía del evaluador de hospitales seguros. Washington, D.C.: PAHO, (C) 2008107 p.-- (Series Hospitals Safe from Disasters, 1) ISBN 978-92-75-13256-2. [En línea]. Disponible en: http://www.paho.org/spanish/dd/ped/SafeHosEvaluatorGuideSpa.pdf. [Última consulta 14/06/2011] 